\title{
Elaboração e avaliação de biscoitos sem glúten a partir de farelo de arroz e farinhas de arroz e de soja
}

\author{
Elaboration and evaluation of gluten-free cookies made with rice bran \\ and rice and soy flours
}

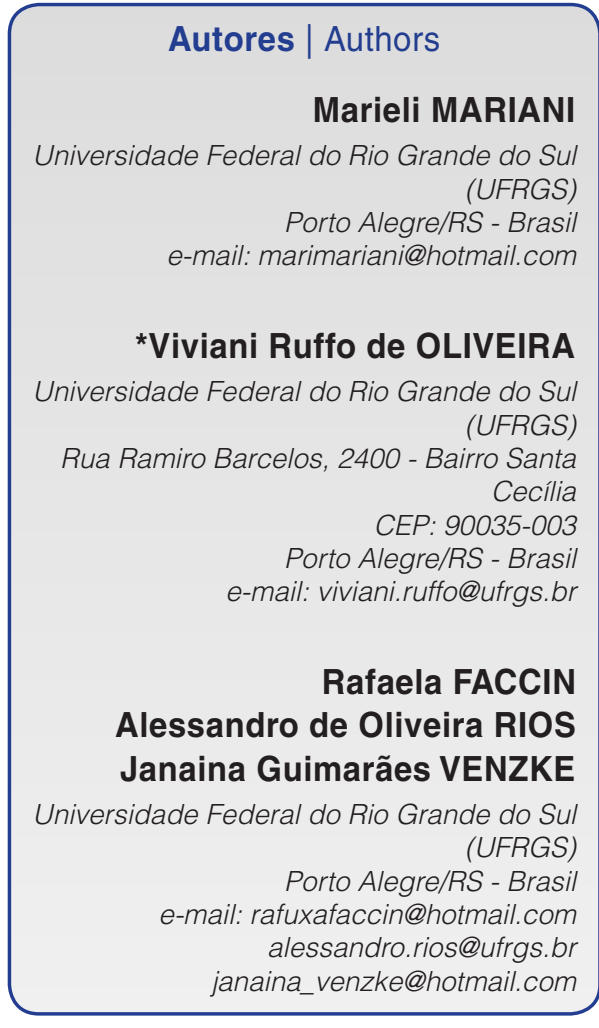

*Autor Correspondente / Corresponding Author

Recebido: Nov. 11, 2014

Aprovado: Abr. 10, 2015

\section{Resumo}

A exclusão do glúten da dieta é um grande desafio, pois muitos produtos que o contém fazem parte dos hábitos alimentares da população. Esse trabalho teve como objetivo avaliar as características físicas, químicas e sensoriais de biscoitos sem glúten, elaborados a partir de farinha de arroz, farelo de arroz e farinha de soja. Foram elaboradas quatro formulações: FT- padrão (trigo); FAFS- farinhas de arroz e de soja; FEFS- farelo de arroz e farinha de soja (1:1); FAFEFS- farinhas de arroz e de soja e farelo de arroz (1:1:1). Foram avaliados os seguintes parâmetros físicos: peso pós-cocção, diâmetro e espessura pós-cocção, e fator de expansão. Foram determinadas as quantidades de umidade, proteínas, lipídios, cinzas e carboidratos. Na análise sensorial, avaliou-se os atributos de aparência, cor, textura, sabor e aceitação global, e a intenção de compra. Em relação aos parâmetros físicos, FAFEFS apresentou diferença estatística significativa $(p<0,05)$ quanto ao aumento de diâmetro e fator de expansão. Quanto às análises químicas, FEFS apresentou valores estatisticamente significativos $(p<0,05)$ quanto ao teor proteico. Sobre a aceitabilidade, os biscoitos dos tratamentos alternativos não diferiram estatisticamente do padrão. Os biscoitos do tratamento FAFEFS obtiveram maior porcentagem de intenção de compra. Pode-se concluir, portanto, que os biscoitos elaborados com farelo de arroz e farinha de soja (FEFS) como substituto de farinha de trigo, se caracterizaram como uma alternativa viável do ponto de vista nutricional e sensorial.

Palavras-chave: Doença celíaca; Bolachas sem glúten; Desenvolvimento de produtos.

\section{Summary}

The exclusion of gluten from the diet is a great challenge, since a lot of products that contain it are part of the population's food habits. The objective of this work was to evaluate the physical, chemical and sensory properties of gluten-free cookies, made with rice flour, rice bran and soy flour. Four formulations were made: FT- standard (wheat); FAFS- rice flour (50\%) and soy flour (50\%); FEFS- rice bran (50\%) and soy flour (50\%); FAFEFS- rice flour (33\%), soy flour (33\%) and rice bran (33\%). The following physical parameters were evaluated: weight loss after cooking, increased diameter and thickness after cooking, and the expansion factor. The moisture, protein, fat, ash and carbohydrate contents were also determined. In the sensory analysis the attributes of appearance, colour, texture, flavour and overall acceptance were evaluated and the purchase intent determined. Regarding the physical parameters, FAFEFS showed statistically different results for the increase in diameter and expansion factor. As for the chemical analyses, FEFS showed statistically different values for the protein and dietary fibre contents. With respect to acceptability, the alternative treatments did not differ from the standard. The FAFEFS cookies showed the highest percentages for purchase intention. It can be concluded that cookies made with rice bran and soybean flour (FEFS) as a substitute for wheat flour are a viable alternative from the nutritional and sensory points of view.

Key words: Celiac disease; Gluten free cookies; Product development. 


\section{Introdução}

A doença celíaca (DC), até 1970, apresentava prevalência global na população de $0,03 \%$ (TACK et al., 2010). Atualmente, acredita-se que essa prevalência varie entre $0,5-1,26 \%$ na Europa e Estados Unidos (LUDVIGSSON e GREEN, 2011). É considerada uma enteropatia crônica autoimune, a doença do trato intestinal caracterizada principalmente pela inflamação do intestino delgado e induzida por intolerância à ingestão de alimentos que contenham proteínas do glúten encontradas principalmente no trigo, aveia, triticale, centeio e cevada (CATASSI e FASANO, 2008; POLANCO, 2008).

Na presença de DC, os alimentos que contêm glúten devem ser substituídos por outros, como por exemplo: milho, arroz, soja, batata e mandioca, de forma que a dieta atenda às necessidades nutricionais de acordo com a idade do indivíduo (FARO, 2008; LA BARCA et al., 2010).

Contudo, a remoção de trigo da dieta por toda a vida se torna um grande desafio para os profissionais da área de alimentos (LA BARCA et al., 2010), pois produtos que fazem parte dos hábitos alimentares da população, como: pães, bolos, biscoitos, pizzas e massas, são normalmente elaborados a partir de farinha de trigo. $\mathrm{Na}$ impossibilidade do consumo do trigo, geralmente se utiliza a farinha de arroz nessas preparações, por ser uma das opções mais bem aceitas para a elaboração de produtos para celíacos. Além de não ser alergênica, a farinha de arroz é um produto versátil, tem sabor suave, baixos níveis de sódio e alta proporção de amido facilmente digerível (NABESHIMA e EL-DASH, 2004; SIVARAMAKRISHNAN et al., 2004; OLIVEIRA et al., 2014)

A farinha de arroz é gerada a partir do resíduo denominado "arroz quebrado", o que geraria considerável perda de rendimento na produção do grão polido quando transformado em farinha, e que pode substituir parcial ou totalmente a farinha de trigo em preparações como bolos (SOUZA et al., 2013).

Nos últimos anos, visando evitar a monotonia das preparações para aqueles que não consomem glúten, inseriu-se novos ingredientes; passaram a ser investigados, inclusive, os derivados do arroz, obtidos no beneficiamento e ainda pouco utilizados na alimentação humana, como é o caso do farelo de arroz (WALTER et al., 2008). Para Lacerda et al. (2010), trata-se de um produto seguro, do ponto de vista nutricional, microbiológico e sensorial. Para Walter et al. (2008), situa-se nas camadas externas do grão a origem do farelo por polimento, local onde estão presentes as maiores concentrações de proteínas, lipídios, fibra, minerais e vitaminas, enquanto o interior é rico em amido. Por isso, diversos componentes do arroz presentes no farelo têm sido relacionados a diferentes efeitos benéficos no organismo. Lacerda et al. (2010) sugerem ainda que biscoitos elaborados com farelo de arroz extrusado pode ter qualidade sensorial e nutricional.

Entretanto, assim como a farinha de arroz, grandes quantidades de farelo são desprezadas ou vendidas como produto de baixo custo, pois o aproveitamento dos subprodutos do beneficiamento do arroz no Brasil ainda é incipiente e pouco diversificado (SOARES JÚNIOR et al., 2009a).

A soja e os seus produtos vêm sendo amplamente estudados devido ao seu valor nutricional e também às suas propriedades funcionais na indústria de alimentos e como alimento funcional, pois exercem ação moduladora em determinados mecanismos fisiológicos por meio de suas proteínas e isoflavonas (CIABOTTI et al., 2006). Portanto, a farinha de soja é outra excelente opção para elaboração de produtos sem glúten.

O desenvolvimento de novas opções de produtos de panificação com ingredientes alternativos à farinha de trigo torna-se algo cada vez mais desejado por consumidores. Dentre os produtos de panificação, os biscoitos são de grande interesse comercial devido às suas características de produção, consumo, vida de prateleira e aceitação. Muitos desses produtos têm sido criados com a finalidade de melhorar a formulação em termos nutricionais (CATASSI e FASANO, 2008; PEREZ e GERMANI, 2007).

Atualmente, no mercado nacional e internacional, é possível encontrar biscoitos isentos de glúten, porém, muitos produtos disponíveis no mercado não apresentam boa aceitação pelos consumidores (ZUCCO et al., 2011). Além disso, possuem pouco valor nutricional e custo elevado, tornando-se de difícil acesso a populações menos favorecidas economicamente (RODRIGUES FERREIRA et al., 2009).

Por isso, o aproveitamento de produtos derivados de arroz e soja na alimentação humana, utilizando a incorporação destes em formulações de biscoitos, é uma excelente estratégia para aumentar o valor nutricional e conferir características funcionais aos produtos isentos de glúten, sem agregar valores elevados ao produto final. Sendo assim, o presente estudo teve como objetivo avaliar as características físicas, químicas e sensoriais de biscoitos elaborados para pacientes celíacos.

\section{Material e métodos}

\subsection{Matéria-prima}

O farelo de arroz foi cedido pela Indústria Riograndense de Óleos Vegetais Ltda. (Irgovel), sendo este desengordurado, estabilizado e certificado pela mesma. Os demais ingredientes da formulação foram 
Elaboração e avaliação de biscoitos sem glúten a partir de farelo de arroz e farinhas de arroz e de soja MARIANI, M. et al.

obtidos em estabelecimentos comerciais da cidade de Porto Alegre, RS.

\subsection{Elaboração dos biscoitos}

Para as formulações dos biscoitos do tipo cookie adaptou-se a metodologia descrita por Marcílio et al. (2005) e sua elaboração foi realizada no laboratório de Técnica Dietética do curso de Nutrição da Faculdade de Medicina da Universidade Federal do Rio Grande do Sul (UFRGS), após vários testes preliminares, até a adequação dos níveis mínimos e máximos a serem utilizados nas formulações finais, conforme descrito na Tabela 1.

As amostras seguiram um delineamento inteiramente casualizado e foram identificadas como: tratamento padrão (FT), com $130 \mathrm{~g}$ de farinha de trigo; tratamento 1 (FAFS), com $55 \mathrm{~g}$ de farinha de arroz e $55 \mathrm{~g}$ de farinha de soja; tratamento 2 (FEFS), com $55 \mathrm{~g}$ de farelo de arroz e $55 \mathrm{~g}$ de farinha de soja; e tratamento 3 (FAFEFS), elaborado com 36,7g de farinha de arroz, 36,7 $\mathrm{g}$ de farelo de arroz e 36,7 $\mathrm{g}$ de farinha de soja.

Primeiramente, os ingredientes secos foram peneirados e pesados. Para a elaboração dos biscoitos foi utilizado o método creme, misturando em batedeira doméstica Sield ${ }^{\circledR}$, modelo Top Mixer, a manteiga e os açúcares (refinado e mascavo) e batidos em velocidade baixa por 3 minutos, até constituírem uma massa homogênea e macia. Posteriormente, foram acrescentados ao creme o ovo, o leite e a baunilha, misturados por 1 minuto. Por último, foram colocados os outros ingredientes, por 30 segundos, em velocidade baixa, até a massa ficar homogênea.

A massa foi dividida em pequenas porções de aproximadamente $15 \mathrm{~g}$ que foram moldadas em formato circular. Os biscoitos foram assados em fôrmas de alumínio revestidas com papel manteiga em forno de fogão convencional, modelo Luna (Dako $\left.{ }^{\circledR}\right)$, entre o tempo de 18 a 24 minutos, à temperatura de $180^{\circ} \mathrm{C}$, de acordo com testes preliminares.

Após assados, os biscoitos foram resfriados em temperatura ambiente e acondicionados em sacos de polietileno de baixa densidade.

\subsection{Análises químicas}

As análises químicas foram realizadas em triplicata no laboratório de Compostos Bioativos do Instituto Ciência e Tecnologia de Alimentos (ICTA) da Universidade Federal do Rio Grande do Sul (UFRGS). A composição química dos biscoitos foi determinada segundo as normas descritas pelo Instituto Adolfo Lutz (IAL, 2008), por meio dos seguintes procedimentos: umidade em estufa, a $105{ }^{\circ} \mathrm{C}$ até peso constante; cinzas por incineração em mufla, a $550{ }^{\circ} \mathrm{C}$; lipídios por extração direta em Soxleht; as proteínas foram determinadas pelo método de Kjeldahl; e os carboidratos totais foram estimados pelo cálculo da diferença.

\subsection{Análises físicas}

As análises físicas foram realizadas no laboratório de Técnica Dietética do curso de Nutrição da Faculdade de Medicina da Universidade Federal do Rio Grande do Sul (UFRGS). Os biscoitos, provenientes da mesma fornada, foram avaliados em triplicata e escolhidos de forma aleatória, após terem atingido temperatura ambiente. Foram utilizadas três fornadas para cada formulação de biscoito.

As análises físicas realizadas nos biscoitos determinaram o peso, o diâmetro e a espessura, avaliados antes e após a cocção. A pesagem foi realizada em balança digital (escala de 0,1 em 0,1 g), modelo MEA-06290 (Plenna ${ }^{\circledR}$ ). O diâmetro e a espessura

Tabela 1. Formulações dos biscoitos tipo cookie - FT (padrão), FAFS (farinha de arroz + farinha de soja), FEFS (farelo de arroz + farinha de soja) e FAFEFS (farinha de arroz + farelo de arroz + farinha de soja).

\begin{tabular}{|c|c|c|c|c|}
\hline \multirow{2}{*}{ Ingredientes } & \multicolumn{4}{|c|}{ Composição dos biscoitos } \\
\hline & FT & FAFS & FEFS & FAFEFS \\
\hline Farinha de trigo (g) & 130 & - & - & - \\
\hline Farinha de soja (g) & - & 55 & 55 & 36,7 \\
\hline Farinha de arroz (g) & - & 55 & - & 36,7 \\
\hline Farelo de arroz (g) & - & - & 55 & 36,7 \\
\hline Manteiga sem sal (g) & 45 & 45 & 45 & 45 \\
\hline Açúcar mascavo (g) & 31 & 31 & 31 & 31 \\
\hline Açúcar refinado (g) & 45 & 45 & 45 & 45 \\
\hline Ovo fresco $(m L)$ & 25 & 25 & 25 & 25 \\
\hline Fermento químico (g) & 0,8 & 0,8 & 0,8 & 0,8 \\
\hline Leite $(\mathrm{mL})$ & 3,5 & 3,5 & 3,5 & 3,5 \\
\hline Essência de baunilha (mL) & 2,5 & 2,5 & 2,5 & 2,5 \\
\hline
\end{tabular}


foram medidos com o auxílio de um paquímetro (Vernier Caliper ${ }^{\circledR}$ ) e o fator de expansão foi obtido pela razão entre os valores de diâmetro e espessura dos biscoitos.

\subsection{Análise sensorial}

Os biscoitos foram avaliados sensorialmente no laboratório de Técnica Dietética do curso de Nutrição da Faculdade de Medicina da Universidade Federal do Rio Grande do Sul (UFRGS), para os atributos de aparência, cor, textura, sabor e aceitação global. Foi realizado um teste afetivo com 48 avaliadores, entre alunos, docentes e funcionários da própria instituição, não-treinados, não-portadores de doença celíaca, consumidores de biscoitos, e que apresentavam disponibilidade de tempo e motivação em participar.

Cada avaliador recebeu quatro amostras, com os diferentes tratamentos, pesando aproximadamente $14 \mathrm{~g}$ cada, distribuídas aleatoriamente, em pratos brancos descartáveis e identificados com códigos de três dígitos aleatórios. Foi fornecido um copo de água para limpeza das papilas gustativas e uma ficha de avaliação sensorial, a qual continha uma escala estruturada de sete pontos, ancorada pelos eixos: 1, correspondente a "desgostei muitíssimo", e 7, a "gostei muitíssimo" (JONES et al., 1955). Além disso, foi aplicado o teste de intenção de compra do produto por meio de uma pergunta fechada.

Esse estudo foi submetido e aprovado pelos Comitês de Pesquisa e Ética da Universidade Federal do Rio Grande do Sul (UFRGS), conforme a Resolução 466/2012 do CNS/MS, registrado sob protocolo $n^{\circ} 18254$ (BRASIL, 2013).

\subsection{Análise estatística}

Os resultados obtidos foram avaliados por análise de variância e para comparação das médias foi realizado o Teste de Tukey. Os resultados foram avaliados com o nível de significância de 5\% de probabilidade de erro, no software estatístico ESTAT versão 2.0.

\section{Resultados e discussão}

\subsection{Análises físicas}

As análises físicas de peso, diâmetro e espessura pré e pós-cocção e fator de expansão estão apresentados na Tabela 2.

Não foram observadas diferenças de redução de peso pós-cocção entre os tratamentos $(p>0,05)$.

A formulação FAFEFS apresentou maior aumento do diâmetro pós-cocção em relação às demais. As formulações FEFS $(0,79 \mathrm{~mm})$ e FAFS $(0,64 \mathrm{~mm})$ não apresentaram diferença estatística significativa entre si $(p>0,05)$. O tratamento FT apresentou menor aumento do diâmetro $(0,51 \mathrm{~mm})$, sem diferir estatisticamente da formulação FAFS.

Larosa et al. (2006) encontraram valores médios de $40 \mathrm{~mm}$ para o aumento do diâmetro de biscoitos elaborados com farinha de "okara", enquanto os biscoitos-controle, elaborados com farinha de trigo, apresentaram $37 \mathrm{~mm}$. No presente estudo também foi observado aumento do diâmetro em dois tratamentos em relação ao biscoito padrão (FT).

De acordo com a Tabela 2, os tratamentos alternativos não apresentaram diferença significativa $(p>0,05)$ em relação ao aumento de espessura pós-cocção, todavia, o biscoito FT apresentou maior aumento de espessura pós-cocção $(0,24 \mathrm{~mm})$, diferindo estatisticamente apenas da formulação FEFS $(0,14 \mathrm{~mm})$.

Quanto ao fator de expansão, os tratamentos que obtiveram maior expansão foram FAFEFS (5,09\%) e FEFS (4,77\%), entretanto, não apresentaram diferença estatística significativa $(p>0,05)$ entre si. Os biscoitos FAFS (4,45\%) e FT (4,39\%) apresentaram menor fator de expansão, porém também não apresentaram diferença estatística $(p>0,05)$ em relação ao FEFS $(4,77)$.

No estudo de Medeiros (2009), os biscoitos com farinha de trigo apresentaram maior fator de expansão $(38,52 \%)$ do que os biscoitos elaborados com concentrações de $15 \%(36,48 \%)$ e $20 \%$ (36,37\%) de polpa de pequi desidratada $(p<0,05)$. Esse resultado difere do

Tabela 2. Parâmetros físicos dos biscoitos FT (padrão), FAFS (farinha de arroz + farinha de soja), FEFS (farelo de arroz + farinha de soja) e FAFEFS (farinha de arroz + farelo de arroz + farinha de soja).

\begin{tabular}{lcccc}
\multicolumn{1}{c}{ Parâmetros físicos avaliados } & FT & \multicolumn{2}{c}{ Tratamentos } \\
Redução de peso pós-cocção $(\mathrm{g})$ & $1,55^{\mathrm{a}} \pm 0,30$ & $1,74^{\mathrm{a}} \pm 0,64$ & $1,42^{\mathrm{a}} \pm 0,38$ & $1,90^{\mathrm{a}} \pm 0,09$ \\
Aumento do diâmetro pós-cocção $(\mathrm{mm})$ & $0,51^{\mathrm{c}} \pm 0,058$ & $0,64^{\mathrm{bc}} \pm 0,23$ & $0,79^{\mathrm{b}} \pm 0,08$ & $1,07^{\mathrm{a}} \pm 0,10$ \\
Aumento da espessura pós-cocção $(\mathrm{mm})$ & $0,24^{\mathrm{a}} \pm 0,053$ & $0,19^{\mathrm{ab}} \pm 0,18$ & $0,14^{\mathrm{b}} \pm 0,07$ & $0,17^{\mathrm{ab}} \pm 0,05$ \\
Fator de expansão $(\%)$ & $4,39^{\mathrm{b}}$ & $4,45^{\mathrm{b}}$ & $4,77^{\mathrm{ab}}$ & $5,09^{\mathrm{a}}$ \\
\hline
\end{tabular}

Letras iguais na mesma linha indicam não haver diferença significativa para $p<0,05 . \pm$ Desvio-padrão. 
encontrado no presente estudo, em que os biscoitos com farinha de trigo apresentaram menor fator de expansão em relação aos demais tratamentos.

Para Rasper (1991), o diâmetro, a espessura e a expansão de biscoitos tipo cookie têm sido utilizados para predizer a qualidade dos produtos. Biscoitos com fator de expansão muito alto ou muito baixo causam problemas na indústria, resultando em produtos com tamanho pequeno ou peso muito elevado. Além disso, para Moraes et al. (2010), uma vantagem quando se trabalha com os biscoitos é que eles não precisam apresentar elevada quantidade de glúten, como é o caso das farinhas utilizadas para a elaboração dos pães.

\subsection{Análises químicas}

Os resultados da avaliação da composição química dos biscoitos estão apresentados na Tabela 3.

Os tratamentos que apresentaram maior umidade foram $\operatorname{FAFS}(7,96 \%)$ e $\operatorname{FEFS~}(7,36 \%)$ não havendo diferença estatística significativa entre si $(p>0,05)$. O tratamento FAFEFS apresentou $7,06 \%$ de umidade, havendo diferença estatística significativa $(p<0,05)$ em relação ao FAFS. O biscoito FT obteve menor umidade $(6,45 \%)$ demonstrando diferença estatística significativa $(p<0,05)$ em relação ao FAFS e FEFS. Os valores obtidos nesse trabalho apresentaram-se situados dentro do teor de umidade máxima para biscoitos, que é de 14\% (BRASIL, 1978).

De acordo com Cauvain e Young (2002), a absorção de água por produtos de panificação depende principalmente do conteúdo de proteína que absorve aproximadamente o seu peso em água. Em relação ao conteúdo proteico, as amostras apresentaram diferença estatística significativa entre si $(p<0,05)$. O biscoito FEFS apresentou maior teor proteico $(14,22 \%)$, seguido dos biscoitos FAFS (11,96\%) e FAFEFS $(11,16 \%)$. O biscoito FT apresentou menor quantidade de proteínas, apenas $7,35 \%$, dentre todas as formulações, concordando com as análises de Mauro et al. (2010).

Lacerda et al. (2009) verificaram variação proteica crescente à medida que se aumentava a quantidade de farelo de arroz extrusado nos biscoitos elaborados. 0 teor médio de proteínas nos biscoitos elaborados com quantidades crescentes de farelo de arroz extrusado variou entre 6,36-7,56g/100 $\mathrm{g}$ de biscoito, com maior conteúdo encontrado no biscoito com $50 \%$ do ingrediente alternativo.

A soja, além da qualidade proteica, possui características químicas e nutricionais que a qualificam como um alimento funcional. Friedman e Brandon (2001) sugerem que a soja pode ser utilizada de forma preventiva e terapêutica no tratamento de doenças cardiovasculares, câncer, osteoporose, sintomas da menopausa, além de possuir outros benefícios Além disso, segundo Ju et al. (2001), as proteínas do arroz e da soja são de grande importância, pois são hipoalergênicas.

Quanto ao teor de lipídios, as formulações FAFS, FEFS e FAFEFS continham, respectivamente, 22,13\%, $21,82 \%, 20,29 \%$, de lipídios em sua composição, não diferindo estatisticamente $(p>0,05)$ entre si. Entretanto, apresentaram teor lipídico significativamente maior do que o tratamento $\mathrm{FT}(17,47 \%)$.

O conteúdo lipídico de alimentos pode variar conforme os ingredientes utilizados. Silva et al. (2001) relataram que em biscoitos elaborados com 10\% de substituição da farinha de trigo por farinha de jatobá, o teor lipídico dos biscoitos variou entre 27,99-28,38\%, incluindo o biscoito-controle, o que implica em valores maiores dos que os verificados nesse trabalho.

Em relação à gordura, quando o grão não é parboilizado ocorre rancidez em curto período. Contudo, Bhanger et al. (2008) e Lemos e Souza-Soares (2000) ressaltam que o farelo de arroz apresenta componentes antioxidantes e funcionais. Além disso, o farelo de arroz utilizado na elaboração dos biscoitos do presente estudo foi desengordurado e estabilizado.

O maior teor lipídico dos tratamentos alternativos em relação ao padrão pode ser justificado pela composição centesimal da farinha de soja que foi utilizada nos três tipos de tratamento. Segundo a Tabela Brasileira de Composição dos Alimentos (UNICAMP, 2011), a farinha de soja apresenta $14,6 \%$ de lipídios em sua composição e a farinha de trigo $1,4 \%$.

Tabela 3. Composição química dos biscoitos FT (padrão), FAFS (farinha de arroz + farinha de soja), FEFS (farelo de arroz + farinha de soja) e FAFEFS (farinha de arroz + farelo de arroz + farinha de soja).

\begin{tabular}{|c|c|c|c|c|}
\hline \multirow{2}{*}{ (\%) } & \multicolumn{4}{|c|}{ Tratamentos } \\
\hline & FT & FAFS & FEFS & FAFEFS \\
\hline Umidade & $6,45^{c} \pm 0,88$ & $7,96^{a} \pm 0,56$ & $7,36^{\mathrm{ab}} \pm 0,47$ & $7,06^{b c} \pm 0,46$ \\
\hline Proteínas & $7,35^{\mathrm{d}} \pm 0,17$ & $11,96^{b} \pm 0,32$ & $14,22^{a} \pm 0,08$ & $11,16^{c} \pm 0,18$ \\
\hline Lipídios & $17,47^{b} \pm 1,5$ & $22,13^{a} \pm 0,59$ & $21,82^{a} \pm 1,01$ & $20,29^{a} \pm 0,37$ \\
\hline Cinzas & $0,58^{d} \pm 0,07$ & $1,56^{c} \pm 0,09$ & $4,23^{a} \pm 0,14$ & $3,03^{b} \pm 0,07$ \\
\hline Carboidratos & $65,16^{a} \pm 0,078$ & $45,99^{c} \pm 0,06$ & $37,27^{d} \pm 0,04$ & $48,20^{b} \pm 0,036$ \\
\hline
\end{tabular}

Letras iguais na mesma linha indicam não haver diferença significativa entre os resultados, para $p<0,05 . \pm$ Desvio-padrão. 
O conteúdo de cinzas nos biscoitos foi crescente à medida que maior quantidade de farelo de arroz foi sendo acrescentado à formulação, havendo diferença estatística significativa $(p<0,05)$ entre todos os tratamentos. 0 biscoito que obteve maior conteúdo de cinzas foi o FEFS $(4,23 \%)$, seguido dos biscoitos FAFEFS $(3,03 \%)$ e FAFS $(1,56 \%)$. O biscoito FT apresentou menor quantidade de cinzas, apenas 0,58\%.

Soares Júnior et al. (2009b) obtiveram resultados semelhantes quanto às cinzas em biscoitos elaborados com até $50 \%$ de farinha de casca de pequi, para os quais os resultados variaram de forma crescente, oscilando entre 2,4-2,9g/100 g, à medida que a farinha de trigo foi substituída pela de casca de pequi. O mesmo foi relatado por Galdeano e Grossmann (2006) em biscoitos elaborados com $20 \%$ de casca de aveia extrusada em que o teor de cinzas encontrado foi $3,15 \mathrm{~g} / 100 \mathrm{~g}$.

Hoffpauer (2005) ressalta que o conteúdo de cinzas de um alimento expressa o resíduo inorgânico que permanece após a queima da matéria orgânica. O farelo de arroz possui quantidade significativa de minerais como fósforo, magnésio, potássio, ferro, manganês e zinco.

Quanto ao teor de carboidratos (Tabela 3), todos os tratamentos tiveram diferença estatística significativa entre si $(p<0,05)$. O maior conteúdo de carboidratos foi observado no FT $(65,16 \%)$. Os biscoitos FAFEFS e FAFS apresentaram teor de carboidratos de 48,20\% e 45,99\%, respectivamente. A formulação com menor teor glicídico foi a FEFS $(37,27 \%)$.

Em biscoitos salgados elaborados com adição de $10 \%, 15 \%$ e $20 \%$ de farinha de berinjela, Perez e Germani (2007) obtiveram valores de carboidratos decrescentes $(62,31 \mathrm{~g} / 100 \mathrm{~g}, 59,40 \mathrm{~g} / 100 \mathrm{~g}$ e 55,49g/100 g) à medida que a farinha de trigo foi substituída pela de berinjela, e o teor de fibra alimentar foi crescente $(6,72 \mathrm{~g} / 100 \mathrm{~g}$, $8,22 \mathrm{~g} / 100 \mathrm{~g}$ e $9,30 \mathrm{~g} / 100 \mathrm{~g}$ ).

Feddern et al. (2007) destacam que a composição química do farelo de arroz varia de acordo com o tipo de arroz e as técnicas de moagem utilizadas. Lee e Newman (2003) relatam ainda que existe correlação entre as propriedades físico-químicas e as propriedades funcionais das proteínas, especialmente as da soja, que podem ser alteradas, favoravelmente ou não, de acordo com a temperatura, a secagem, os métodos de preparação ou outros tratamentos durante o processamento e estocagem dos produtos.

\subsection{Análise sensorial}

Na Tabela 4, é possível observar as médias das notas atribuídas às amostras quanto aos atributos avaliados nos tratamentos: aparência, cor, textura, sabor e aceitação global.

De acordo com a Tabela 4, os tratamentos não diferiram estatisticamente entre si $(p>0,05)$ em relação à aparência. Os tratamentos obtiveram escore médio de 5,0, o que corresponde ao critério "gostei regularmente".

No estudo de Lacerda et al. (2009), biscoitos elaborados com 12,5\%, 25\%, 37,5\% e 50\% de substituição de farinha de trigo e fécula de mandioca por farelo de arroz desengordurado obtiveram escores relacionados à aparência de 6,0 e 7,0, referentes a "gostei ligeiramente" e "gostei regularmente", em uma escala hedônica estruturada com 9 pontos.

$\mathrm{Na}$ avaliação do atributo cor do presente estudo, os tratamentos alternativos não apresentaram diferença estatística significativa entre si, apresentando-se em média a nota 5,0 para essa característica. A formulação padrão apresentou média de nota inferior quanto à cor, entretanto não houve diferença estatística com o tratamento FAFS.

Foi observado que mesmo os tratamentos com coloração mais escura foram aceitos pelos avaliadores. A diferença da cor se deve, possivelmente, à tonalidade do farelo de arroz, mais escuro do que as farinhas utilizadas nesse estudo.

Esse resultado corrobora o de Rodrigues Ferreira et al. (2009), que no estudo sobre a adição de farinha de sorgo em cookies de chocolate obtiveram diferença estatística significativa $(p<0,05)$ para o atributo cor quando comparado à amostra comercial (trigo), atribuindo o resultado à coloração mais intensa da farinha de sorgo.

Tabela 4. Escores médios dos atributos sensoriais dos biscoitos FT (padrão), FAFS (farinha de arroz + farinha de soja), FEFS (farelo de arroz + farinha de soja) e FAFEFS (farinha de arroz + farelo de arroz + farinha de soja).

\begin{tabular}{|c|c|c|c|c|}
\hline \multirow{2}{*}{ Atributos sensoriais } & \multicolumn{4}{|c|}{ Tratamentos } \\
\hline & FT & FAFS & FEFS & FAFEFS \\
\hline Aparência & $4,90^{a} \pm 1,47$ & $5,10^{a} \pm 1,43$ & $5,48^{a} \pm 1,94$ & $5,29^{a} \pm 1,57$ \\
\hline Cor & $4,58^{b} \pm 1,15$ & $4,94^{\mathrm{ab}} \pm 1,56$ & $5,46^{a} \pm 1,60$ & $5,33^{a} \pm 1,09$ \\
\hline Textura & $5,23^{a} \pm 1,21$ & $4,12^{a} \pm 1,24$ & $4,02^{b} \pm 1,49$ & $5,23^{a} \pm 0,96$ \\
\hline Sabor & $5,13^{a} \pm 1,60$ & $4,42^{a} \pm 1,30$ & $4,40^{a} \pm 1,73$ & $5,17^{a} \pm 1,52$ \\
\hline Aceitação global & $5,17^{\mathrm{ab}} \pm 1,06$ & $4,50^{b} \pm 1,29$ & $4,63^{a b} \pm 1,68$ & $5,23^{a} \pm 1,13$ \\
\hline
\end{tabular}

Letras diferentes na mesma linha indicam haver diferença significativa para $p<0,05 . \pm$ Desvio-padrão. 
Quanto à textura, apresentada na Tabela 4, os tratamentos FAFS e FAFEFS também apresentaram escore médio 5,0, correspondente ao "gostei regularmente", não apresentando diferença estatística significativa $(p>0,05)$ em relação ao biscoito FT. Entretanto, o tratamento FEFS obteve média inferior, correspondendo à opção "indiferente" na escala, havendo diferença estatística significativa $(p<0,05)$ em relação aos outros.

Soares Júnior et al. (2009a) verificaram redução nos escores médios relacionados ao atributo textura em pães à medida que a farinha de trigo foi substituída por farelo de arroz torrado e, atribuíram como uma das causas dessa redução, as características tecnológicas das fibras e seus efeitos sobre outros componentes do alimento. Destacam, ainda, a necessidade de adequar um maior nível de fibra com a menor mudança possível nas características sensoriais, principalmente a textura de alimentos alternativos, tornando o produto aceitável pelo consumidor.

Apesar de se ter realizado vários testes laboratoriais preliminares, sugere-se que outra possível causa do problema relacionado à textura dos biscoitos do presente estudo seja o tempo de forneamento. Portanto, o tratamento com farelo de arroz pode ter apresentado menor média em relação à textura devido à maior dureza, requerendo menor tempo de forneamento do que os outros tratamentos.

Em relação ao atributo sabor, não foi demonstrada diferença estatística significativa $(p>0,05)$ entre os tratamentos. Os tratamentos alternativos FAFS, FEFS e FAFEFS apresentaram escores médios entre 4,0 e 5,0 correspondendo à opção "indiferente" e "gostei regularmente".

Rodrigues Ferreira et al. (2009), avaliando o potencial de farinha de sorgo em biscoitos, observaram que $100 \%$ dos avaliadores com doença celíaca atribuíram valores iguais ou superiores a 7,0 para as amostras estudadas.

Sudha et al. (2007) elaboraram biscoitos com 20\%, $30 \%$ e $40 \%$ de substituição da farinha de trigo por farelo de arroz desengordurado que não foram bem aceitos em relação ao gosto e à impressão sensorial deixada pelo alimento na boca. Possivelmente, o farelo de arroz quando extrusado apresenta sabor mais suave, ou seja, com menor conteúdo de compostos que provocam sabor residual, do que quando são utilizados outros tratamentos para estabilização do farelo de arroz. Cabe ressaltar ainda, que o farelo de arroz utilizado no presente estudo também foi desengordurado.

Marcílio et al. (2005) observaram em seu estudo que o amaranto, apesar de ser uma matéria-prima pouco utilizada no Brasil, também possui potencial para

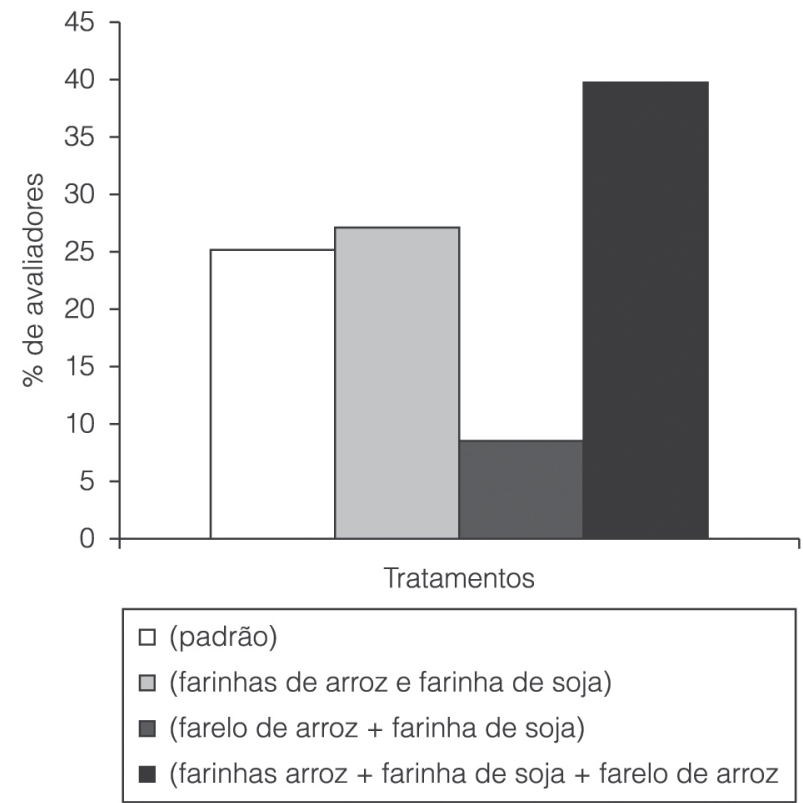

Figura 1. Porcentagem de intenção de compra dos tratamentos FT, FAFS, FEFS e FAFEFS.

elaboração de biscoitos para pessoas com intolerância ao glúten.

Quanto à aceitação global (Tabela 4), os tratamentos FAFEFS $(5,23)$, FEFS $(4,63)$ e FAFS $(4,50)$ não apresentaram diferença estatística significativa $(p>0,05)$ em relação ao FT $(5,17)$, sendo que os escores médios foram de aproximadamente 5,0 pontos, correspondendo a "gostei regularmente". O biscoito FAFS demonstrou diferença estatística significativa $(p<0,05)$ em relação ao FAFEFS.

Quanto à intenção de compra (Figura 1), foi observado que a maioria dos avaliadores compraria o biscoito FAFEFS (farinha de arroz, farelo de arroz e farinha de soja), enquanto que o que recebeu a menor intenção de compra foi o biscoito FEFS (farelo de arroz + farinha de soja).

Lee e Newman (2003) ressaltam que os portadores da doença celíaca têm dificuldade de dar sequência ao tratamento dietético devido à escassez de produtos isentos de glúten e os impactos negativos dessa restrição alimentar na qualidade de vida. Nesse estudo, apenas $25 \%$ dos avaliadores optaram pelo produto com farinha de trigo, os outros $75 \%$ optaram por algum dos tratamentos alternativos, sendo eles possíveis opções de produtos isentos de glúten.

\section{Conclusões}

Os biscoitos à base de farinhas de arroz e de soja e de farelo de arroz (FAFEFS) apresentaram aumento de diâmetro e do fator de expansão. 
Elaboração e avaliação de biscoitos sem glúten a partir de farelo de arroz e farinhas de arroz e de soja MARIANI, M. et al.

Quanto às análises químicas, os biscoitos elaborados com farelo de arroz e farinha de soja (FEFS) apresentaram características promissoras em relação ao teor proteico e às cinzas.

$\mathrm{Na}$ análise sensorial, apenas o atributo textura do biscoito elaborado com farelo de arroz e farinha de soja (FEFS) foi considerado inferior ao biscoito padrão, pois os outros tratamentos alternativos foram considerados, pelos avaliadores, com qualidade semelhante ao biscoito padrão nos demais atributos, enquanto que os biscoitos elaborados a partir de farinhas de arroz e de soja e de farelo de arroz (FAFEFS) obtiveram maior intenção de compra.

\section{Referências}

BHANGER, M. L.; IQBAL, S.; ANWAR, F.; IMRAN, M.; AKHTAR, M.; ZIA-UL-HAQ, M. Antioxidant potential of rice bran extracts and its effects on stabilization of cookies under ambient storage. International Journal of Food Science \& Technology, Osney Mead, v. 43, n. 5, p. 779-786, 2008. http://dx.doi.org/10.1111/ j.1365-2621.2007.01515.x.

BRASIL. Comissão Nacional de Normas e Padrões para Alimentos. Resolução - CNNPA n 12, de 24 de julho de 1978. Aprova as normas técnicas especiais. Diário Oficial [da] República Federativa do Brasil, Brasília, DF, 24 jul. 1978. Disponível em: <http://portal.anvisa.gov.br/wps/wcm/connect/ e57b7380474588a39266d63fbc4c6735/RESOLUCAO_12_1978. pdf?MOD=AJPERE> . Acesso em: 4 dez. 2013.

BRASIL. Ministério da Saúde. Conselho Nacional de Saúde - CNS. Resolução n 466, de 12 de dezembro de 2012. Diretrizes e normas regulamentadoras de pesquisa em seres humanos. Diário Oficial [da] República Federativa do Brasil, Brasília, DF, 13 jun. 2013. p. 59. Seção 1, n. 112. Disponível em: <http://bvsms.saude.gov.br/bvs/saudelegis/cns/2013/ res0466_12_12_2012.html>.

CATASSI, C.; FASANO, A. Celiac disease. Current Opinion in Gastroenterology, London, v. 24, n. 6, p. 687-691, 2008. http:// dx.doi.org/10.1097/MOG.0b013e32830edc1e. PMid:19122516

CAUVAIN, S. P.; YOUNG, L. Fabricación de pan. Zagoza: Acribia, 2002.

CIABOTTI, S.; BARCELLOS, M. F. P.; MANDARINO, J. M. G.; TARONE, A. G. Avaliações químicas e bioquímicas dos grãos, extratos e tofus de soja comum e de soja livre de lipoxigenase. Ciência e Agrotecnologia, Lavras, v. 30, n. 5, p. 920-929, 2006.

FARO, H. C. Doença celíaca: revisão bibliográfica. 2008. 95 f. Monografia (Especialização em Pediatria)-Hospital Regional da Asa Sul, Brasília, 2008.

FEDDERN, V.; FURLONG, E. B.; SOARES, L. A. S. Efeitos da fermentação nas propriedades físico-químicas e nutricionais do farelo de arroz. Ciência e Tecnologia de Alimentos, Campinas, v. 27 , n. 4, p. 800-804, 2007. http://dx.doi.org/10.1590/S010120612007000400020.

FRIEDMAN, M.; BRANDON, D. L. Nutritional and health benefits of soy proteins. Journal of Agricultural and Food Chemistry, Washington, v. 49, n. 3, p. 1069-1086, 2001. http://dx.doi. org/10.1021/jf0009246. PMid:11312815

GALDEANO, M. C.; GROSSMANN, M. V. E. Oat hulls treated with alkaline hydrogen peroxide associated with extrusion as fiber source in cookies. Ciência e Tecnologia de Alimentos, Campinas, v. 26, n. 1, p. 123-126, 2006.

HOFFPAUER, D. W. New applications for whole rice bran. Cereal Foods World, Minneapolis, v. 50, n. 4, p. 173-174, 2005.

INSTITUTO ADOLFO LUTZ - IAL. Normas analíticas do Instituto Adolfo Lutz: métodos químicos e físicos para análise de alimentos. 5. ed. São Paulo, 2008. 1020 p.

JONES, L. V.; PERYAM, D. R.; THURSTONE, L. L. Development of a scale for measuring soldiers ' food preferences. Journal of Food Science, Champaign, v. 20, n. 5, p. 512-520, 1955. http:// dx.doi.org/10.1111/j.1365-2621.1955.tb16862.x.

JU, Z. Y.; HETTIARACHCHY, N. S.; RATH, N. Extraction, denaturation and hydrophobic properties of rice flour proteins. Journal of Food Science, Champaign, v. 66, n. 2, p. 229-232, 2001. http://dx. doi.org/10.1111/j.1365-2621.2001.tb11322.x.

LA BARCA, A. M.; ROJAS-MARTÍNEZ, M. E.; ISLAS-RUBIO, A. R.; CABRERA-CHÁVEZ, F. Gluten-free breads and cookies of raw and popped amaranth flours with attractive technological and nutritional qualities. Plant Foods for Human Nutrition, Dordrecht, v. 65, n. 3, p. 241-246, 2010. http://dx.doi. org/10.1007/s11130-010-0187-z. PMid:20734143

LACERDA, D. B. C. L.; SOARES JÚNIOR, M. S.; BASSINELLO, P. Z.; CASTRO, M. V. L.; SILVA-LOBO, V. L.; CAMPOS, M. R. H.; SIQUEIRA, B. S. Qualidade de farelos de arroz cru, extrusado e parboilizado. Pesquisa Agropecuária Tropical, Goiânia, v. 40, n. 4, p. 521-530, 2010.

LACERDA, D. B. C. L.; SOARES, J. M. S.; BASSINELLO, P. Z.; SIQUEIRA, B. S.; KOAKUZU, S. N. Qualidade de biscoitos elaborados com farelo de arroz torrado em substituição à farinha de trigo e fécula de mandioca. Archivos Latinoamericanos de Nutrición, Caracas, v. 59, n. 2, p. 199-205, 2009.

LAROSA, G.; ROSSI, E. A.; BARBOSA, J. C.; CARVALHO, M. R. B. Aspectos sensoriais, nutricionais e tecnológicos de biscoito doce contendo farinha de "okara". Alimentos e Nutrição, Araraquara, v. 17, n. 2, p. 151-157, 2006.

LEE, A.; NEWMAN, J. M. Celiac diet: its impact on quality of life. Journal of the American Dietetic Association, Bethesda, v. 103, n. 11, p. 1533-1535, 2003. http://dx.doi.org/10.1016/j. jada.2003.08.027. PMid:14576723 
Elaboração e avaliação de biscoitos sem glúten a partir de farelo de arroz e farinhas de arroz e de soja MARIANI, M. et al.

LEMOS, M. R. B.; SOUZA-SOARES, L. A. Arroz e seus subprodutos na região sul do Brasil. Vetor, Rio Grande, v. 10, p. 21-36, 2000.

LUDVIGSSON, J. F.; GREEN, P. H. R. Clinical management of coeliac disease. Journal of Internal Medicine, v. 269, n. 6, p. 560-571, 2011. http://dx.doi.org/10.1111/j.13652796.2011.02379.x. PMid:21443532

MARCÍLIO, R.; AMAYA-FARFAN, J.; SILVA, M. A. A. P.; SPEHAR, C. A. Avaliação da farinha de amaranto na elaboração de biscoito sem glúten do tipo cookie. Brazilian Journal of Food Technology, Campinas, v. 8, n. 2, p. 175-181, 2005.

MAURO, A. K.; SILVA, V. L. M.; FREITAS, M. C. J. Caracterização física, química e sensorial de cookies confeccionados com farinha de talo de couve (FTC) e farinha de talo de espinafre (FTE) ricas em fibra alimentar. Ciência e Tecnologia de Alimentos, Campinas, v. 30, n. 3, p. 719-728, 2010.

MEDEIROS, P. R. M. S. Composição química e avaliação sensorial de biscoitos elaborados com polpa de pequi (Caryocar brasiliense Camb.) desidratada. 2009. 72 f. Dissertação (Mestrado em Ciência e Tecnologia de Alimentos)Universidade Federal de Goiás, Goiânia, 2009.

MORAES, K. S.; ZAVAREZE, E. R.; MIRANDA, M. Z.; SALASMELLADO, M. M. Avaliação tecnológica de biscoitos tipo cookie com variações nos teores de lipídio e de açúcar Technological evaluation of cookies with lipid and sugar content variations. Ciência e Tecnologia de Alimentos, Campinas, v. 30, p. 233-242, 2010. Suplemento 1.

NABESHIMA, E. H.; EL-DASH, A. A. Modificação química da farinha de arroz como alternativa para o aproveitamento dos subprodutos do beneficiamento do arroz. Boletim do Centro Pesquisa Processamento de Alimentos, Curitiba, v. 22, n. 1, p. 107-120, 2004.

OLIVEIRA, C. A. O.; ANSELMI, A. A.; KOLLING, D. F.; FINGER, M. I. F.; DALLA CORTE, V. F.; DILL, M. D. Farinha de arroz e derivados como alternativas para a cadeia produtiva do arroz. Revista Brasileira de Produtos Agroindustriais, Campina Grande, v. 16, n. 3, p. 291-297, 2014.

PEREZ, P. M. P.; GERMANI, R. Elaboração de biscoitos tipo salgado, com alto teor de fibra alimentar, utilizando farinha de berinjela (Solanum melongena, L.). Ciência e Tecnologia de Alimentos, Campinas, v. 27, n. 1, 186-192, 2007

POLANCO, I. Celiac disease. Journal of Pediatric Gastroenterology and Nutrition, Madri, v. 47, p. S3-S6, 2008.

RASPER, V. F. Quality evaluation of cereal and cereal products. In: LORENZ, K. J.; KULP, K. (Ed.). Handbook of cereal science and technology. New York: Marcel Dekker, 1991. p. 595-638.

RODRIGUES FERREIRA, S. M.; LUPARELLI, P. C.; SCHIEFERDECKER, M. E.; VILELA, R. M. Cookies sem glúten a partir da farinha de sorgo. Archivos Latinoamericanos de Nutrición, Caracas, v. 59, n. 4, p. 433-440, 2009. PMid:20677459.

SILVA, M. S.; MARTINS, K. A.; BORGES, S. Utilização tecnológica dos frutos de jatobá-do-cerrado e de jatobá-da-mata na elaboração de biscoitos fontes de fibra alimentar e isentos de açúcares. Ciência e Tecnologia de Alimentos, Campinas, v. 21, n. 2, p. 176-182, 2001

SIVARAMAKRISHNAN, H. P.; SENGE, B.; CHATTOPADHYAY, P. $K$. Rheological properties of rice dough for making rice bread. Journal of Food Engineering, Essex, v. 62, n. 1, p. 37-45, 2004. http://dx.doi.org/10.1016/S0260-8774(03)00169-9.

SOARES JÚNIOR, M. S.; BASSINELLO, P. Z.; CALIARI, M.; GEBIN, P. F. C.; JUNQUEIRA, T. L.; GOMES, V. A.; LACERDA, D. B. C. L. Qualidade de pães com farelo de arroz torrado. Ciência e Tecnologia de Alimentos, Campinas, v. 29, n. 3, p. 636-641, 2009a. http://dx.doi.org/10.1590/S0101-20612009000300028.

SOARES JÚNIOR, M. S.; REIS, R. C.; BASSINELLO, P. Z.; LACERDA, D. B. C. L.; KOAKUZU, S. N.; CALIARI, M. Qualidade de biscoitos formulados com diferentes teores de farinha de casca de pequi. Pesquisa Agropecuária Tropical, Goiânia, v. 39, n. 2, p. 98-104, 2009b.

SOUZA, T. A. C.; SOARES JÚNIOR, M.; CAMPOS, M. R. H.; SOUZA, T. S. C.; DIAS, T.; FIORDA, F. A. Bolos sem glúten a base de arroz quebrado e casca de mandioca Semina. Ciências Agrárias, Londrina, v. 34, n. 2, p. 717-728, 2013.

SUDHA, M. L.; VETRIMANI, R.; LEELAVATHI, K. Influence of fiber from different cereals on the rheological characteristics of wheat flour dough and on biscuit quality. Food Chemistry, London, v. 100, n. 4, p. 1365-1370, 2007. http://dx.doi.org/10.1016/j. foodchem.2005.12.013.

TACK, G. J.; VERBEEK, W. H.; SCHREURS, M. W.; MULDER, C. J. The spectrum of celiac disease: epidemiology, clinical aspects and treatment. Nature Reviews. Gastroenterologia y Hepatologia, London, v. 7, n. 4, p. 204-213, 2010.

UNIVERSIDADE ESTADUAL DE CAMPINAS - UNICAMP. Tabela brasileira de composição de alimentos - TACO. 4. ed. rev. ampl. Campinas: UNICAMP; NEPA, 2011. 161 p. Disponível em: <http://www.unicamp.br/nepa/downloads/taco_4_edicao_ ampliada_e_revisada.pdf?PHPSESSID=b8f2d017fa504c81ac 8ac62eacc27c0e>

WALTER, M.; MARCHEZAN, E.; AVILA, L. A. Arroz: composição e características nutricionais. Ciência Rural, Santa Maria, V. 38, n. 4, p. 1184-1192, 2008. http://dx.doi.org/10.1590/S010384782008000400049 .

ZUCCO, F.; BORSUK, Y.; ARNTFIELD, S. D. Physical and nutritional evaluation of wheat cookies supplemented with pulse flours of different particle sizes. LWT - Food Science and Technology, Campinas, v. 44, n. 10, p. 2070-2076, 2011. 